provide for both the examination of the skeletal material preserved in museums and anatomical collections and the measurement by trained observers of groups of the existing population all over the country. Arrangements will also be made for the reduction and digestion of the material when collected, and for its publication.

THE projected survey is an object which is deserving of strong public support. Not only will the results be of the greatest scientific importance, as they will fill a gap in our knowledge of the composition of the British people which is much to be deplored, but they will also afford data of great significance, and from some points of view essential, in the consideration of a number of social and medical problems. The survey will involve expenditure on instruments, travelling for purposes of observation and publication, towards which contributions are invited from the public in an appeal supported by, among other signatories, Lord Onslow, Lord Raglan, Lord Meston, Sir Richard Gregory, Sir Henry Wellcome and the Rev. Edwin Smith, president of the Royal Anthropological Institute. Contributions should be addressed to the Treasurer, Royal Anthropological Institute, 52 Upper Bedford Place, London, W.C.1.

\section{Expedition to New Guinea}

Prans for the exploration of the country in the neighbourhood of the Sepik River in the mandated territory of New Guinea, which have been in preparation for some time, are now approaching completion; and Mr. G. M. Dyott, the leader, will leave shortly with two other members of the expedition for Australia, where he will be joined at Sydney by Mr. H. L. Williams, the Australian anthropologist, who will complete the personnel of the party. For some time past, the exploration of the Sepik River country has been an object of ambition of anthropologists and geographers alike. The greater part of it is entirely unknown. Last year, Mr. E. W. P. Chinnery, in the course of an official tour of duty as Government anthropologist, penetrated to the eastern boundary of the unknown territory. He reached the summit of Mount Hagen, and in his reports records how from a lofty plateau there he was able to look out over this country.

Mr. ChINNERy came into touch with hitherto undescribed peoples having many remarkable features in their culture, who were still living in the stone age (see NATURE, 134, 328 ; 1934). In the account of his experience which he has since published, he describes signs of occupation in the unvisited tableland below, which point to a system of cultivation differing from anything previously recorded in New Guinea. Mr. Dyott's expedition, in addition to making a plane-table survey of the country traversed, will devote special attention to the culture of the peoples in the Sepik area. It is also hoped to obtain conclusive evidence of the existence of the so-called 'devil-pig', a cloven-footed graminivorous animal, of which Mr. Monckton, formerly a resident magistrate in New Guinea, claimed to have observed the tracks, but of which knowledge otherwise rests on the report of the Papuans. They fear it greatly. The expedition is supported by the Australian Commonwealth Government and the Royal Geographical Society. The collections which the expedition hopes to make will be divided between the Pitt Rivers Museum, Oxford, and certain institutions in Australia.

\section{Vertical Take-off with the Autogiro}

Seĩon dE LA Cierva, lecturing before the Royal Aeronautical Society on March 15, made the first public announcement of the fact that he has produced a type of his autogiro that has achieved direct lift off the ground without any forward run. This was shown by the exhibition of cinema films in which the machine was seen to rise without displacing chocks placed in front of the wheels. Combined with its already proved ability of alighting with a practically negligible run, this makes it possible to visualise aircraft of this type operating from aerodromes of much smaller area, and less carefully kept surface, than hitherto. Sea-going operations, either from rough water or ship decks, are also facilitated by the absence of the need of horizontal run.

THE combination of vertical lift followed by horizontal flight at the desired instant is attained by altering the pitch angle of the horizontal rotating lifting surfaces of the autogiro. These are set at the angle of no lift while the rotor is speeded up by a torque applied from the engine. When the speed of rotation is considerably greater than that necessary for normal horizontal flight, the rotating mechanism is declutched, and simultaneously the angle of the surfaces is set to that for high lift. Thus a lift in excess of the weight of the machine is created, and it rises. When this impulse is expended, the machine would normally begin to descend, but in the meantime the full engine power has been changed back to the normal airscrew, and a thrust sufficient for horizontal flight is operating. This takes charge and the machine continues in horizontal or normal climbing flight at the will of the pilot. The machine appears to leap only three or four feet in the films shown. Señor Cierva suggests that while jumps of the order of 60-100 ft. are theoretically possible without needing prohibitive accelerations, an initial height of about $20 \mathrm{ft}$. is all that practical considerations demand.

\section{Television}

THE recent publication of the report of the Postmaster-General's Committee on Television has aroused considerable interest in this subject not only among those technically interested in radio communication and broadcasting, but also among the general public, who now definitely envisage the prospect of being able to 'look' as well as 'listen'. This interest has naturally given rise to a demand for literature, both technical and popular, on the subject. During the past year or so, however, progress in the technique of television at both the transmitting and receiving end has been so rapid that most of the books at 
present available are useful only in explaining the fundamental principles of television or of illustrating the historical development of the subject, which dates back some sixty years. With the object of temporarily filling this gap in the literature, the issue of the Wireless World of March 8 incorporated as a supplement a "Television Guide", comprising a 30-page booklet giving a simple explanation of the subject adequately illustrated by diagrams and photographs. This guide assumes a knowledge of electricity and the principles of radio communication on the part of the reader; the principles involved in television are clearly explained, together with the use and limitations of mechanical scanning systems. The manner in which the cathode ray oscillograph tube has been introduced into the art is described, with the resulting accelerated progress towards high definition television. The most recent developments of picture transmission technique are dealt with, including Zworykin's iconoscope and Farnsworth's image dissector as alternative scanning systems, and the use of the intermediate cinematograph film for the broadeasting of current events. The trend of this supplement to the Wireless World is definitely to explain the principles of the subject to the future owner of a television receiver, and as such, it may be said to form a useful appendix to the report of the Postmaster-General's Committee.

\section{Safe Passing Speeds for Motor-Cars}

Every driver of a motor-car who desires to pass another car going in the same direction has to consider the problem of whether it is possible or not. Apart from the question of whether there is another car coming round the bend of the road in the opposite direction, he has to consider whether there is sufficient clear space ahead. According to a Science Service message, Dr. H. C. Dickinson, of the U.S. Bureau of Standards, has completed tests to find out how much clear space is necessary. Assuming a speed limit of 45 miles an hour and that cars travelling 50 miles an hour are tolerated, he finds that a distance of $900 \mathrm{ft}$. is required for safe clearance. The time required to pass on a level road depends only on their relative speed of five miles an hour, and is nearly six seconds. If the vehicle ahead is moving at 20 miles an hour the distance required is $650 \mathrm{ft}$., $200 \mathrm{ft}$. being required for the actual passing and $450 \mathrm{ft}$. being the necessary allowance for a car approaching at 50 miles an hour. The Highway Research Board of the U.S. National Research Council points out that, considering the number of roads in the country where clear stretches of $900 \mathrm{ft}$. are rare, there is often a serious risk when passing another car at high speed. In mountainous country, winding and hilly roads would come under this category. Dr. Dickinson's figures apply to a car passing only one car ahead; when long lines of cars 'pile up' on the road, greater distances are required for safe passing.

\section{Library of the University of the Witwatersrand}

THE University of the Witwatersrand was the scene of a disastrous fire three years ago, when the greater part of its library, including the Gubbins and the
Hoernle anthropological collections, was destroyed. Appeals for help led to a very substantial measure of replacement, gratefully acknowledged by the University in a letter to the Appeal Committee in London, which has now issued its final report. In this, the chairman, Sir Frank Heath, observes that, while it is impossible to mention individually all the contributors, including learned, technical and scientific societies in England and America, universities and colleges throughout the British Isles and Canada, industrial firms, industrial research associations, British Government departments and the leading missionary societies having stations in South Africa, very special thanks are due to the British Association, the London School of Economics and Imperial Chemical Industries, Ltd. New College, Oxford, and the Imperial College of Science and Technology helped to defray expenses of collection, packing, transportation and insurance. The Union-Castle Steamship Co. undertook the transport of books at a discount of 50 per cent on the ordinary freight charges, and the High Commissioner for the Union of South Africa lent an office rent-free. The Universities Bureau of the British Empire placed its council room at the disposal of the Committee for its meetings. Besides books and manuseripts, a large quantity of pictures, coins, etc., was collected which will form the nucleus of a Johannesburg municipal museum. Some 32,000 volumes in all were dispatched by the Committee.

\section{A Giant Tortoise}

A FINE specimen of Porter's black tortoise (Testudo nigrita) has just been added to the Tortoise House of the Gardens of the Zoological Society of London. This is one of several species attaining a relatively gigantic size, which, a hundred and fifty years ago, swarmed in the Galapagos Islands, the Mascarene Islands, the Aldabras and the Seychelles. Then they attracted the attention of mariners, who forthwith began to visit these islands and carry away their victims by the boat-load. Exploitation of this kind, whether of tortoises or whales, inevitably ends in extermination. On only a very few of these islands are any survivors to be found to-day. But it fortunately happened that many species were taken to other islands, where they bred. This was the case with the species which has just come to the Zoo. For Capt. Porter, on his voyage from the Galapagos, in 1813, distributed several young tortoises from his stock among the chiefs of the Fiji Islands. Many of these escaped, and bred there. The great size of these animals is shown by the fact that the shell of the various species ranged from three to six and a half feet along the curve. Until its death, a few years ago, the largest living tortoise known was owned by Lord Rothschild. This was a specimen of Testudo daudini, of the South Island of Aldabra, taken, with six others, in 1895. The length of the shell was 55 in., or $67 \frac{1}{2}$ in. over the curve. The total weight was $560 \mathrm{lb}$. But even this was a mere pigmy compared with the extinct fossil tortoise (Colos sochelys atlas) from the Lower Pliocene of the Siwalik Hills, India, which had a shell eight feet in length. 